\title{
Evaluation of a comprehensive nondominant hand skills training program
}

\author{
Ellen Mitchell-Krever MA, J Michael Lacroix PhD C Psych ARP CCRC \\ Centre for Adult Remedial Education, Toronto, Ontario
}

\section{E Mitchell-Krever, JM Lacroix. Evaluation of a comprehensive nondominant hand skills training program. Can J Plast Surg 1998;6(4):191-195.}

A program to teach hand skills with the nondominant hand to patients with significant injuries to the dominant hand was evaluated. Fifty-three patients participated. Highly significant effects of training were observed with respect to all dependent skills variables. Age and sex were noncontributory, with all ages and both sexes exhibiting significant improvements with training. Questionnaire data indicated a high degree of satisfaction with the program, and that the training led to a high rate of vocational success. Surgeons may consider hand skills training programs for their patients with significant dominant hand limitations

Key Words: Dominance, Nondominant hand, Rehabilitation, Skills training

\section{Évaluation d'un programme global d'acquisition des habiletés de la main non dominante}

RÉSUMÉ : Un programme d'enseignement des habiletés de la main non dominante à l'intention des patients ayant subi une importante lésion à la main dominante a été évalué. Cinquante-trois patients y ont participé. On a pu observer les effets très significatifs du programme sur toutes les variables liées aux habiletés. L'âge et le sexe n'ont pas influé sur les résultats, tous les groupes d'âge et les deux sexes ont obtenu d'importantes améliorations avec la formation. Les données tirées de questionnaires ont fait état d'un fort degré de satisfaction à l'endroit du programme et la formation a donné lieu à un taux élevé de réussite sur le plan des activités professionnelles. Les chirurgiens peuvent envisager le recours à des programmes de réadaptation des habiletés manuelles pour leurs patients qui souffrent de restrictions marquées de leur main dominante.

$\mathrm{T}$ he hand is the most frequently injured part of the body, with hand injuries accounting for approximately $22 \%$ of all industrial injuries (1). Treatment of a hand injury typically follows well established medical protocols: surgery, followed by physiotherapy, and possibly prosthetic and occupational therapy directed to the injured limb. Rarely, if ever, is attention given to the uninjured limb. Patients may eventually be told that they will have to live with their limitations and that they should learn to rely on the uninjured limb more; however, training for the uninjured limb is not typically included in treatment.

The Centre for Adult Remedial Education (CARE), a

Correspondence and reprints: Dr J Michael Lacroix, Director, Centre for Adult Remedial Education, 1054 Center Street, Suite 150, Thornhill, Ontario L4B 8E5. E-mail lacroixm@istar.ca clinic that is associated with a psychology practice and whose director is a psychologist, was established in Toronto 1990. CARE offers a comprehensive nondominant hand skills training program for clients with significant injury and limitations to the dominant hand/limb. The program borrows heavily from the fundamental principles of skills acquisition developed in other contexts $(2,3)$. It does not have a physiotherapy or occupational therapy focus because the uninjured limb is fully functional. Its core components include perceptuomotor skills to develop various functions of the nondominant hand, handwriting and keyboarding (1). Each program is individualized to suit the needs of the client; specific exercises, the rate of progress and the inclusion of other components (literacy or numeracy upgrading, microcomputer software skills, etc) vary from client to client.

Typically, individuals who have injured their dominant 
hand (usually in the workplace) are referred to CARE after all medical interventions have been completed or are near completion and it has been determined that the patient will have significant limitations in dominant hand functioning. Two separate intake evaluations include a screening interview, if a full psychological assessment has not been carried out, followed by an assessment of functioning with the uninjured hand. In addition, the client's likely future vocational path is considered so that hand training can be optimally tailored to the job. Exclusion criteria for the program include significant psychological sequelae (major depression or severe post-traumatic stress disorder), chemical dependency that would deleteriously affect training, poor motivation and medical problems with the nondominant hand in addition to the difficulties with the dominant hand (eg, bilateral carpal tunnel syndrome).

Following an assessment and testing period, an individualized nondominant hand skills program with a 1:1 instructor to student ratio is developed. The program aims to enhance nondominant hand function in activities of daily living while also targeting the client's vocational goal(s); for example, training for clients aiming at bookkeeping work would place relatively greater emphasis on keypadding. Clients' needs vary and, as such, so do the specific components of their programs (perceptuomotor program only, complete hand program or hand program supplemented with an academic upgrading component or computer training), hours of daily instruction ( 2 to $4 \mathrm{~h}$ ), and program length (typically three to six months). Nonetheless, there is a core curriculum common to all programs. Perceptuomotor programs typically cover basic skills (fine- and gross-motor skills) along with keypadding, and strength and endurance building. The complete hand program also typically includes typing (keyboarding) and handwriting. Instructors follow the protocols specified in CARE's 'Nondominant Hand Skills Assessment and Training Manual' (1996), but make modifications to meet individual goals and needs better.

Although we are aware of similar programs more recently developed (notably the Dominance Transfer program of the Ontario Workers' Compensation Board), we are unaware of any evaluative research published on such programs, and a MEDLINE search as well as searches of other databases through the internet yielded no information or evaluations for similar programs. Thus, this study appears to provide the first evaluation of a nondominant hand skills training program.

\section{MATERIALS AND METHODS}

\section{Subjects}

Data from 53 patients enrolled in CARE's nondominant hand skills training program between March 1992 and August 1995 were collected during the summer of 1995. Subjects were from a variety of socioeconomic backgrounds, ranging in ages from 20 to 59 years; 31 males and 22 females participated in the study. Forty-nine patients were right-handed and four were left-handed. Fourteen of the patients were crush victims, 13 were amputees, 18 suffered from a variety of soft tissue conditions, and eight fell in residual categories.

\section{Dependent measures}

Dependent variables were measured both pre- and postnondominant hand training. Variables encompassed six skill areas with a total of 11 different measures of psychomotor functioning clustered within these areas. In addition, information about the patients' employment situation postprogram was obtained through a questionnaire.

\section{Gross-motor and manipulation skill cluster}

The gross-motor transfer test (peg transfer) is modified from the manual dexterity subtest of the General Aptitude Test Battery (GATB) (Canada Employment and Immigration Commission and the Department of Supply Services, 1983). The peg transfer test assesses manual dexterity and involves unimanual peg transfer (in rows from left to right and top to bottom) from a filled tray on the left to an empty tray on the right. The percentage of pegs transferred in $45 \mathrm{~s}$ from a possible number of 48 pegs is calculated.

The gross-motor manipulation test (peg turn) is also modified from the manual dexterity subtest of the GATB. The peg turn test assesses manual dexterity and involves unimanual manipulation of the same pegs as referenced above in a $35 \mathrm{~s}$ period. The percentage of pegs turned is calculated.

\section{Fine-motor and manipulation skill cluster}

The fine-motor assembly test (rivets and washers) is modified from the finger dexterity subtest of the GATB. The test assesses finger dexterity and involves unimanual grasping and assembly movements using small rivets and washers. The percentage of units grasped and assembled in $150 \mathrm{~s}$ from a possible 50 units is calculated.

The O'Connor finger dexterity test measures the time it takes to pick up sets of three miniature rods unimanually and insert them into a 100 hole board (Lafayette Instrument Company, Indiana). The speed at which the board is filled is calculated, and the raw score is transformed into a percentile ranking compared with norms for same-sex subjects using the dominant hand in industrial settings. The norms are provided by Lafayette.

\section{Tests requiring both fine- and gross-motor manipulation skills}

The O'Connor Tweezer Dexterity Test measures the time it takes to pick up individual miniature rods with long tweezers and place them in small holes on a board (Lafayette Instrument Company, Indiana). The time taken to complete this task is calculated and transformed into a percentile ranking compared with norms for same-sex subjects using the dominant hand in industrial settings. The norms are provided by Lafayette.

The Purdue Pegboard Test (Purdue University, Indiana) requires the transfer of small rods from a well to evenly spaced holes in a vertical line (4). Three short trials are completed, and raw scores are converted to percentile rankings compared with norms for same-sex subjects using the dominant hand in industrial settings. The norms are provided by Lafayette. 


\section{Writing skill cluster}

The manuscript writing test involves the reproduction of a short standardized paragraph using manuscript lower and upper case letters using the nondominant hand. The number of words/min is calculated by dividing the number of words by the total time required to copy the paragraph (one word equals five letters, including punctuation and spaces).

The cursive writing test involves the reproduction of a short standardized paragraph using cursive lower and upper case letters. The number of words/min is calculated by dividing the number of words by the total time required to copy the paragraph (one word equals five letters, including punctuation and spaces).

\section{Keyboarding skill cluster}

The typing test is a computer-generated typing test (limited to letters and common punctuation). The test is completed unimanually, and speed (words/min) and accuracy are calculated (typing speed and typing accuracy).

The keypadding test is a computer-generated number keypadding test that is completed unimanually, and a unit measures/min and accuracy are calculated (keypadding speed and keypadding accuracy).

\section{Strength}

The dynamometer test (grip) is used to obtain an index of general hand, wrist and arm strength (Lafayette Instrument Company, Indiana). The patient is instructed to grip the handle of a dynamometer and to "squeeze as hard as you possibly can". The average of three trials is calculated to obtain an average score of kilograms pressed, which is then compared with norms for same age and sex subjects using the dominant hand. The norms are provided by Lafayette.

\section{Follow-up questionnaire}

Graduates were asked to complete an anonymous questionnaire that asked about their employment situation postCARE. For example, did they begin a job hunt, return to their previous employer or did they work for a new employer? If working, did they have a job similar to their preinjury position or was it a different job? Graduates were also asked to rate their training program experience on several measures. For example, how important was the program in improving the use of their nondominant hand and did they feel the instruction was competent?

\section{Data analysis}

The main analyses consisted of MANOVAs to examine the effects of nondominant hand training on the various skill clusters, taking into account age, gender and program type. $t$-tests were then conducted on strength and handedness, as well as on the program variables (program length and daily instruction time). Due to the unequal sample sizes, Levine's test for equality of variances was conducted; if theLevine test was significant, the $t$-test for unequal means was then used. $\mathrm{P}<0.01$ was adopted for statistical significance.
TABLE 1

Mean \pm SD pre- and post-test scores for all dependent measures

\begin{tabular}{|c|c|c|c|}
\hline Skill cluster & Test & $\begin{array}{c}\text { Pretest } \\
(\text { mean } \pm \text { SD })\end{array}$ & $\begin{array}{c}\text { Post-test } \\
(\text { mean } \pm \text { SD })\end{array}$ \\
\hline \multirow{2}{*}{$\begin{array}{l}\text { Gross motor } \\
\text { skills }\end{array}$} & Peg transfer & $53.68 \pm 10.97$ & $87.43 \pm 11.10^{*}$ \\
\hline & Peg turn & $49.53 \pm 12.21$ & $89.06 \pm 10.63^{*}$ \\
\hline \multirow[t]{2}{*}{ Fine motor skills } & $\begin{array}{l}\text { Rivets and } \\
\text { washers }\end{array}$ & $41.85 \pm 11.76$ & $77.30 \pm 13.66^{*}$ \\
\hline & Finger dexterity & $26.11 \pm 24.43$ & $61.97 \pm 29.74 *$ \\
\hline \multirow{2}{*}{$\begin{array}{l}\text { Fine and gross } \\
\text { motor skills }\end{array}$} & Purdue & $13.77 \pm 17.35$ & $42.93 \pm 26.10^{*}$ \\
\hline & Tweezer & $10.40 \pm 17.61$ & $38.55 \pm 29.71 *$ \\
\hline \multirow[t]{2}{*}{ Writing skills } & Manuscript & $7.27 \pm 2.68$ & $15.42 \pm 4.95^{*}$ \\
\hline & Cursive & $7.44 \pm 3.26$ & $14.82 \pm 6.05^{*}$ \\
\hline \multirow{4}{*}{$\begin{array}{l}\text { Typing/ } \\
\text { keypadding } \\
\text { skills }\end{array}$} & Typing speed & $8.21 \pm 4.79$ & $17.83 \pm 8.05^{*}$ \\
\hline & Typing accuracy & $94.92 \pm 4.78$ & $95.00 \pm 4.75$ \\
\hline & Keypadding speed & $10.73 \pm 5.26$ & $30.71 \pm 13.85^{*}$ \\
\hline & $\begin{array}{r}\text { Keypadding } \\
\text { accuracy }\end{array}$ & $95.21 \pm 9.41$ & $96.17 \pm 3.45$ \\
\hline Strength & Grip & $32.57 \pm 14.36$ & $36.97 \pm 13.68^{*}$ \\
\hline
\end{tabular}

*P<0.001

\section{Training effects}

\section{RESULTS}

Table 1 presents the major results of the study, namely preand post-training performance on all dependent measures. Multivariate analysis of variances (MANOVAs) yielded significant effects of training on all skill clusters. Furthermore, training effects were found on every test within a given skill cluster, with the exception of the typing and keypadding accuracy tests.

\section{Demographic variables}

Despite the fact that there were some pretraining effects of age in predictable directions (ie, older subjects were generally slower) (5), age was not related to post-test performance except for manuscript writing, suggesting that nondominant hand skills training is effective regardless of age. Similarly, except for the predictable sex effect (6) on the strength measure (men were stronger than women both pre- and posttraining), sex effects were not significant for any of the tests, either pre- or post-test, suggesting that the effects of training are similar for both men and women. Finally, with respect to handedness, only three of the 26 possible comparisons between right- and left-handed individuals met significance (one pre- and two postmeasures). In view of the small number of left-handers and the unequal number of left- and right-handers, these results were not considered meaningful.

\section{Program variables}

$t$-tests were conducted to examine whether the length of training programs had an impact on performance outcomes. As noted earlier, because of the individualized nature of cli- 
ent programming, program length varied (range two to six months, with a mean of five months). For this analysis, the program length variable was collapsed into two categories: three months and under, and over three months. No pretraining comparisons met the $\mathrm{P}<0.01$ level of significance. However, significant post-test results were found for four of the 11 psychomotor variables, and one other approached significance: postrivets and washers $(\mathrm{t}=-3.29, \mathrm{P}<0.01)$; postmanuscript $(\mathrm{t}=-2.73, \mathrm{P}<0.01)$; post-typing speed $(\mathrm{t}=-3.76$, $\mathrm{P}<0.001)$; postkeypadding speed $(\mathrm{t}=-3.65, \mathrm{P}<0.001)$; and postcursive $(\mathrm{t}=-2.24, \mathrm{P}<0.05)$. An examination of the means showed that, in all cases, clients in the longer programs did better than clients in the shorter programs.

MANOVAs examined differences between program types on perceptuomotor skills, ie, basic perceptuomotor program, complete hand program, hand program supplemented with academic upgrading or computer training. The only significant differences related to pretraining differences with respect to prekeypadding speed test $(\mathrm{F}=5.89, \mathrm{P}<0.01)$ and prekeypadding accuracy $(\mathrm{F}=6.60, \mathrm{P}<0.01)$. Post hoc comparisons (Scheffe) showed that clients scheduled for the perceptuomotor group were slower and less accurate than clients in the other two groups. There were no significant differences between any of the three groups post-test, suggesting that all three programs are equally effective in developing motor skills in the nondominant hand.

Finally, $t$ tests evaluated the training effect of hours of daily skills instruction ( $2 \mathrm{~h}$ versus more than $2 \mathrm{~h}$ daily). The only significant result related to initial differences with respect to keypadding speed $(\mathrm{t}=-2.61, \mathrm{P}<0.01)$ : clients in the group slated to receive more than $2 \mathrm{~h}$ of daily instruction were faster than clients in the group scheduled to receive $2 \mathrm{~h}$ of instruction. Interestingly, no significant differences were found for any of the post-test comparisons, suggesting that little is added to skills development by going beyond $2 \mathrm{~h}$ of daily instruction in nondominant motor skills; it may be that the impact of factors such as fatigue begins to offset the effects of practice after about $2 \mathrm{~h}$.

\section{Follow-up questionnaire}

CARE graduates were asked to complete anonymously a questionnaire about their experience. Because the study sampled graduates from 1992 to 1995, questionnaires were sent on average about one-and-a-half to two years following program completion. Approximately $20 \%$ of the questionnaires were returned. All respondents indicated that they would recommend the program highly to others with similar injuries. All patients felt the program was important in improving the use of the nondominant hand, with $70 \%$ agreeing strongly and $30 \%$ agreeing moderately. In addition, the majority of patients felt the program was helpful in restoring normal family and social functioning, with $40 \%$ agreeing strongly, $40 \%$ agreeing moderately and $20 \%$ neutral. The program was thought by $100 \%$ of the participants to be helpful in becoming ready for employment.

The respondents were also asked what they specifically liked about the program. Specifically identified were the low student to instructor ratio (1:1), the nature of the instruction and teacher support and encouragement. Students also liked the keyboarding/computer and handwriting components of the program. Graduates were also asked what they found most helpful about the program. Responses fall into one of three areas: hand skills development (keyboarding, handwriting, fine-motor skills and general ability to use the nondominant hand); student self-confidence; and teacher support and encouragement.

Graduates were also asked about vocational endeavours following the program. Upon graduation, $67 \%$ went on to school, $22 \%$ returned to work with the preaccident employer at their previous job and $11 \%$ returned to work with the accident employer at a new position. At the time of the evaluation, $44 \%$ of respondents were still attending school and 55\% were working. Of those who were working, $60 \%$ had returned to their preaccident employer and $40 \%$ were working for a new employer; $50 \%$ were working in a capacity similar to their preaccident occupation and $50 \%$ were working in a new capacity altogether.

\section{DISCUSSION}

The major contribution of this study is the demonstration that it is possible, through systematic motor skills programming, to improve significantly the function and use of the nondominant hand following serious injury to the dominant limb. While the statistics obtained with the CARE program may not be directly applicable to other programs, the point is that useful, generalizable skills can be taught. The skills that can be taught include basic perceptuomotor skills, as well as handwriting and keyboarding/keypadding, and these can be learned sufficiently well that patients can successfully go on to further schooling and/or return to work. Elements of the present program that participants considered important to their success include an environment conducive to learning and competent one-on-one instruction. Some individual components of the program (ie, keyboarding and handwriting) also received specific mention. Staff support and encouragement were clearly significant in patient commitment to the goals of programming.

In terms of psychomotor skills, there was a significant training effect for almost every test, with the exception of typing accuracy and keypadding accuracy. Not only did the mean performances improve statistically with training, but in fact, every patient improved on almost every test. With respect to the exceptions (the typing and keyboarding accuracy measures), pretest scores were already quite high and were effectively at 'ceiling' (95\%), albeit at a low rate of speed, so that training effects could impact only on the speed measures. Futhermore, it seems that the program worked equally well across the age range and for both sexes, although the usual age and sex differences were found on pretesting $(5,6)$.

As with more typical motor skills training, longer training programs generally led to better psychomotor performance, with respect to both fine-motor, and fine- and gross-motor tests, as well as the keypadding speed measure. While length of programming had a significant impact on nondominant 
hand skills development, the amount of daily instruction time did not, possibly because of the impact of extraneous factors such as fatigue. This suggests that there is little benefit to going beyond $2 \mathrm{~h}$ of daily one-on-one instruction, provided that the training is done appropriately. However, if more than $2 \mathrm{~h}$ of daily instruction had no incremental effect on nondominant hand skills, the addition of other training components to the hand program clearly did not interfere with motor skills development: there were essentially no differences between the three types of programs with respect to hand skills. This means that patients can undergo both hand training and more vocationally focused training at the same time, with the proviso that the different components are adequately integrated.

In addition to specific psychomotor skills, the questionnaire data indicated indirect benefits of training the nondominant hand to those with serious dominant hand injuries. Secondary benefits included improved self-confidence, improved ability to carry out activities of daily living, and restored normal family and social functioning. These added benefits likely stemmed not only from learning to use the nondominant hand, and thereby re-establishing independence in daily tasks, but from the vocational reintegration that was made possible through this process. In this context, the impact of nondominant hand skills training on vocational reintegration was clearly very beneficial, because all patients were either in a school/retraining program or had returned to work within a few months of program completion.
In sum, nondominant hand skills training following dominant hand injury can greatly enhance the effectiveness of rehabilitation efforts. This type of training has not been part of traditional medical management following hand injuries, in part because it is new and, for the most part, untried. Now that CARE has demonstrated program effectiveness when done properly, surgeons can consider adding similar programs to their medical and rehabilitation armamentorium.

ACKNOWLEDGEMENTS: The authors thank Beth Avery, Mary McGoey and Jennifer Dexter for the initial version of this program, and Mary McGoey, Jennifer Dexter, Ellen Luk, Margeau Dyer, Charlotte Goldfried and Markita Fleming for its more recent version.

\section{REFERENCES}

1. Gloss DS, Wardle MG. Use of the Minnesota Rate of Manipulation Test for disability evaluation. Percept Mot Skills 1982;55:527-32.

2. Schank RC, Abelson RP. Scripts, Plans, Goals and Understanding: An Inquiry into Human Knowledge Structures. Hillsdale: Lawrence Erlbaum, 1977.

3. Schmidt RA. A schema theory of discrete motor learning. Psychol Rev 1975;82:225-60.

4. Tiffin J. The Purdue Pegboard Test. Lafayette: Purdue University, 1948.

5. Kauranen K, Vanharanta $\mathrm{H}$. Influences of aging, gender, and handedness on motor performance of upper and lower extremities. Percept Mot Skills 1996;82:515-25.

6. Harkonen R, Piirtomaa M, Alarantar H. Grip strength and hand position of the dynamometer in 204 Finnish adults. J Hand Surg (Br) 1993;18:129-32. 